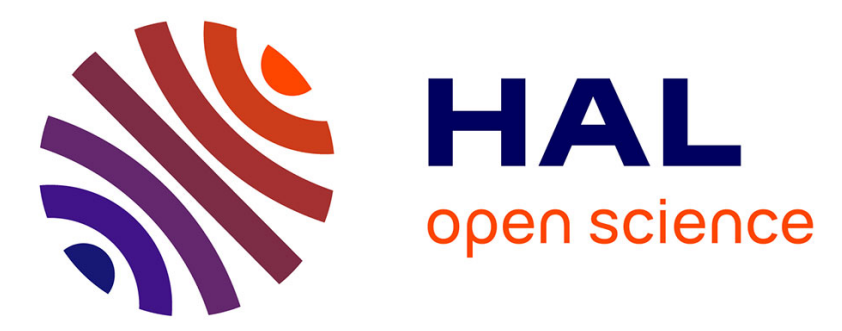

\title{
Correlations between structural changes and dielectric behavior of thermally aged XLPE
}

Youcef Kemari, Abdelouahab Mekhaldi, G. Teyssedre, Madjid Teguar

\section{To cite this version:}

Youcef Kemari, Abdelouahab Mekhaldi, G. Teyssedre, Madjid Teguar. Correlations between structural changes and dielectric behavior of thermally aged XLPE. IEEE Transactions on Dielectrics and Electrical Insulation, 2019, 26 (6), pp.1859-1866. 10.1109/TDEI.2019.008189 . hal-02503843

\section{HAL Id: hal-02503843 \\ https://hal.science/hal-02503843}

Submitted on 12 Nov 2020

HAL is a multi-disciplinary open access archive for the deposit and dissemination of scientific research documents, whether they are published or not. The documents may come from teaching and research institutions in France or abroad, or from public or private research centers.
L'archive ouverte pluridisciplinaire HAL, est destinée au dépôt et à la diffusion de documents scientifiques de niveau recherche, publiés ou non, émanant des établissements d'enseignement et de recherche français ou étrangers, des laboratoires publics ou privés. 


\title{
Correlations Between Structural Changes and Dielectric Behavior of Thermally Aged XLPE
}

\author{
Youcef Kemari $^{1}$, Abdelouahab Mekhaldi ${ }^{1}$, Gilbert Teyssèdre ${ }^{2}$ and Madjid Teguar $^{1}$ \\ ${ }^{1}$ Laboratoire de Recherche en Electrotechnique, Ecole Nationale Polytechnique d'Alger, 10 Avenue Hassen Badi, B.P 182, \\ El-Harrach, 16200 Algiers, Algeria. \\ ${ }^{2}$ LAPLACE (Laboratoire Plasma et Conversion d'Énergie), Université de Toulouse, CNRS; Bat 3R3, 118 route de Narbonne, \\ F-31062 Toulouse cedex 9, France.
}

\begin{abstract}
This study aims at elucidating the correlations between structural changes and the variation of dielectric properties of cross-linked polyethylene (XLPE) during thermal aging. For this purpose, thermal aging experiments were carried out on XLPE samples at 80, 100, 120 and $140{ }^{\circ} \mathrm{C}$ for different aging times for a maximum total duration of 5040 hours. Chemical changes were assessed by Fourier Transform Infrared Spectrum (FTIR). Besides, the crystallinity ratio and the melting temperature were evaluated using Differential Scanning Calorimetry (DSC). Frequency domain dielectric spectroscopy was used to investigate the evolution of the dielectric constant and losses of XLPE during aging. The results show that aging at 80 and $100{ }^{\circ} \mathrm{C}$ could help to improve the crystalline state of XLPE which leads to the decrease of the dielectric constant. However, for higher thermal stress, the main aging mechanism of XLPE is thermal oxidation which leads to deteriorate the morphology and increase both the polarization and losses, mainly at low frequencies. It has been found also that in some cases, the non-homogeneity of the color of XLPE seems to indicate the increase of interfaces in the material which could lead to increase the dielectric losses due to the interfacial polarization.
\end{abstract}

Index Terms - power cable insulation, cross-linked polyethylene insulation, aging, Fourier spectroscopy, calorimetry, dielectric measurements, dielectric materials

\section{INTRODUCTION}

POWER cables represent an important part of electrical transmission and distribution networks. Moreover, the use of polymeric insulation materials in underground cables offers a significant reduction of the electrical system volume [1] Therefore, special attention has been paid to the continuous development of insulating materials used in power cables. Among these materials, cross-linked polyethylene (XLPE) remains a material of choice for medium and high-voltage cables [2]. In fact, XLPE presents many advantages such as a low dissipation factor of about $0.03 \%$ at $20{ }^{\circ} \mathrm{C}$, low dielectric constant of 2.2-2.5, good thermo-mechanical properties and high operating temperature of about $90^{\circ} \mathrm{C}[3]$.

However, irreversible changes may occur after the exposure of the cable to a variety of stresses. Among them, the thermal constraint is considered as one of the most severe factors leading to change the properties of the insulation and then to the deterioration of the cable [4]. To address these issues, many researchers have focused on physicochemical analyses to study the morphology changes in XLPE due to aging [5-7]. These studies showed that the main degradation mechanisms in XLPE are thermal oxidation and scission of the molecular chains. In addition, some researchers have investigated the dielectric response of XLPE during thermal aging $[4,8-9]$ This approach has revealed the evolution of some dielectric parameters (e.g. conductivity, losses factor, dielectric constant...) with aging.

To our knowledge, the large number of works already done in this area were based on experimental databases collected from samples that have been aged in a very accelerated manner or for short periods $[10,11]$ which could lead to skip some intermediate changing states of XLPE properties during the aging process. Besides, some aging mechanisms not in operation in normal service conditions can be triggered by overstressing. Especially the evolution of the material can substantially change when going through the melting temperature range.

The study of correlations between structural changes and dielectric properties represents an important task for the development of more resistant materials and additives in order to increase the insulation lifetime. Such a study could help to predict the dielectric properties according to physicochemical 
changes and vice versa and to contribute to the development of diagnosis tools for aging monitoring.

Through this paper, we focused in particular on the physicochemical and the dielectric behaviors of XLPE material versus aging. The selected material is a commercial XLPE used for the insulation of medium voltage cables. Samples were subjected to a controlled thermal aging at four different temperatures ranging from 80 to $140{ }^{\circ} \mathrm{C}$ and at different aging times for a maximum total duration of 5040 hours (210 days).

Moreover, our work consists of evaluating the physicochemical and dielectric properties of the samples before and after aging in order to characterize the degree of degradation of XLPE. Besides, we aim to study the correlations between these different properties, which leads to a better understanding of aging and degradation mechanisms.

\section{EXPERIMENTAL}

\subsection{MATERIALS AND SAMPLES PREPARATION}

The studied material is intended for the extrusion of power cables operated in phase to phase voltage of $U=30 \mathrm{kV}$ (i.e. $U_{0}$ $=18 \mathrm{kV}$ between the phase and the screen). The base materials are pellets of cross-linkable resin (LE4201R, manufactured by Borealis company). These pellets are loaded with di-cumyl peroxide (DCP) as cross-linking agent with $2 \%$ in content. The material contains also di-tert-butyl peroxide and Irganox antioxidant. Samples were manufactured in thick plaque form and supplied by ENICAB Subsidiary company of General Cable of Biskra, Algeria.

For manufacturing the XLPE plaques, the pellets were preheated for 5 minutes at $125^{\circ} \mathrm{C}$ then molded and crosslinked at $185{ }^{\circ} \mathrm{C}$ under a pressure of $300 \mathrm{MPa}$ using a pressurized heat press. These conditions (300 MPa and 185 ${ }^{\circ} \mathrm{C}$ ) are maintained for about 10 minutes to ensure complete cross-linking of the material. At the end, the press is cooled with water by maintaining always the same pressure.

The diameter of the obtained circular plates of XLPE is 12.9 $\mathrm{cm}$, whereas their thickness is $(2 \pm 0.2) \mathrm{mm}$. In order to perform physicochemical and electrical experiments, the XLPE plates were cut into circular shaped samples with a diameter of about $46 \mathrm{~mm}$ and a thickness of $(2 \pm 0.2) \mathrm{mm}$. Samples were cut using a cutting press with a circular cutting die tool.

\subsection{THERMAL AGING EXPERIMENTS}

Accelerated thermal aging was performed according to IEC 60216 standard [12]. The circular samples were vertically arranged inside air-circulating ovens at aging temperatures of 80,100 and $120^{\circ} \mathrm{C}$. Samples were taken out every 1008 hours (42 days) for total aging time of 5040 hours (210 days).

Moreover, since the degradation process of XLPE is very fast at $140{ }^{\circ} \mathrm{C}$, samples were taken out every 504 hours $(21$ days) for a total period of 1512 hours (63 days). All these samples are intended for FTIR and dielectric spectroscopy tests. On the other hand, DSC characterization was performed on unaged and aged samples that have been taken at the final stage of aging at each temperature (after 5040 hours at 80, 100 and $120^{\circ} \mathrm{C}$ and after 1512 hours at $140{ }^{\circ} \mathrm{C}$ ).

\subsection{FOURIER TRANSFORM INFRARED SPECTRUM CHARACTERIZATION (FTIR)}

FTIR characterizations were carried out using a Vertex 70 FTIR spectrometer from Bruker equipped with a platinum diamond accessory. Moreover, our samples present relatively large thickness of about $2 \mathrm{~mm}$ which imposed us to use FTIR analysis in Attenuated Total Reflection (ATR) mode.

All samples were analyzed and each experiment started with a background spectrum acquisition without the sample. Then, 24 scans were recorded in the wavenumber range of $430-5000 \mathrm{~cm}^{-1}$ with a resolution of $2 \mathrm{~cm}^{-1}$ for each sample. The obtained ATR-FTIR spectra represent the average of three spectra recorded from three different samples that have been aged in the same conditions (temperature and time).

\subsection{DIFFERENTIAL SCANNING CALORIMETER (DSC)}

The variations of phase transitions of XLPE due to thermal aging have been monitored using differential scanning calorimetry DSC 2010 TA Instruments with a computer data system. Samples of about $10 \mathrm{mg}$ of weight were analyzed by two repeated heating and cooling cycles at a constant rate of $10{ }^{\circ} \mathrm{C} / \mathrm{min}$ under nitrogen atmosphere in the temperature interval $20-150{ }^{\circ} \mathrm{C}$. The DSC thermogram obtained in the first heating run is strongly influenced by the thermal history of the material. Therefore, we based the analysis on the second heating/cooling cycle to determine the DSC parameters such as the crystallinity rate and the melting temperature.

\subsection{FREQUENCY DOMAIN DIELECTRIC SPECTROSCOPY}

The dielectric spectroscopy measurements were performed using Novocontrol Alfa-A High Performance Analyzer dielectric spectrometer with a ZGS active sample cell. The system can control the temperature under nitrogen atmosphere by a Quatro cryosystem within $\pm 0.1{ }^{\circ} \mathrm{C}$. In addition, the control and the evaluation of dielectric measurements were done using WinDETA ${ }^{\circledR}$ software. Prior to the dielectric measurements, gold electrodes were deposited onto both surfaces of the XLPE circular samples by sputtering. The diameter and the thickness of the sputtered electrodes are respectively $35 \mathrm{~mm}$ and $30 \mathrm{~nm}$. For the sake of evaluating the dielectric response of XLPE samples with thermal aging, dielectric constant $\varepsilon^{\prime}{ }_{r}$ and dielectric losses $\tan (\delta)$ were measured in the frequency range $10^{-2}$ to $10^{5} \mathrm{~Hz}$ at $20^{\circ} \mathrm{C}$.

\section{RESULTS AND DISCUSSIONS}

\subsection{COLOR CHANGES}

Figure 1 shows the changes in aspect of XLPE samples at different aging stages. We observe that the color changed from gray before aging to light yellow after $5040 \mathrm{~h}$ at $80{ }^{\circ} \mathrm{C}$ and then to light orange after $5040 \mathrm{~h}$ at $100{ }^{\circ} \mathrm{C}$. On the other hand, the color has become darker at $120^{\circ} \mathrm{C}$. Also, it can be noticed that after $5040 \mathrm{~h}$ at $120^{\circ} \mathrm{C}$ and $504 \mathrm{~h}$ at $140{ }^{\circ} \mathrm{C}$, XLPE color is a dark orange that is not uniformly distributed over the surface of the aged sample. 


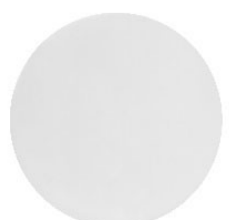

(a)

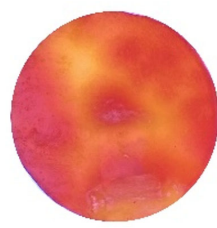

(d)

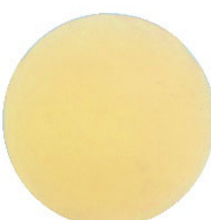

(b)

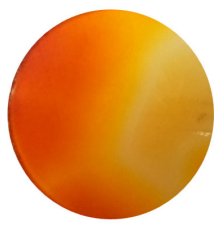

(e)

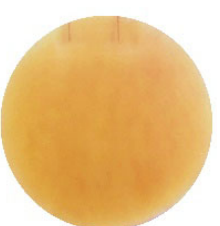

(c)

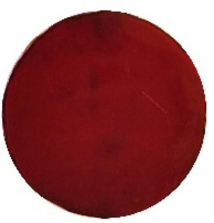

(f)
Figure 1. Color change of XLPE samples: (a) before aging, (b) aged at $80{ }^{\circ} \mathrm{C}$ for $5040 \mathrm{~h}$, (c) aged at $100{ }^{\circ} \mathrm{C}$ for $5040 \mathrm{~h}$, (d) aged at $120{ }^{\circ} \mathrm{C}$ for $5040 \mathrm{~h}$, (e) aged at $140{ }^{\circ} \mathrm{C}$ for $504 \mathrm{~h},(\mathrm{e})$ aged at $140{ }^{\circ} \mathrm{C}$ for $1512 \mathrm{~h}$

Moreover, the change in color at $140{ }^{\circ} \mathrm{C}$ is much faster and a dark-brown color has been obtained after $1512 \mathrm{~h}$. These changes have been attributed to the formation of vinylidene and vinyl groups due to degradation by thermal oxidation $[10$, 13]. It could correspond to the reaction of the antioxidant during the oxidation phase [14].

\subsection{ATR-FTIR SPECTROSCOPY ANALYSIS}

The FTIR spectra of XLPE samples before and after thermal aging are presented in Figure 2. Before identifying the
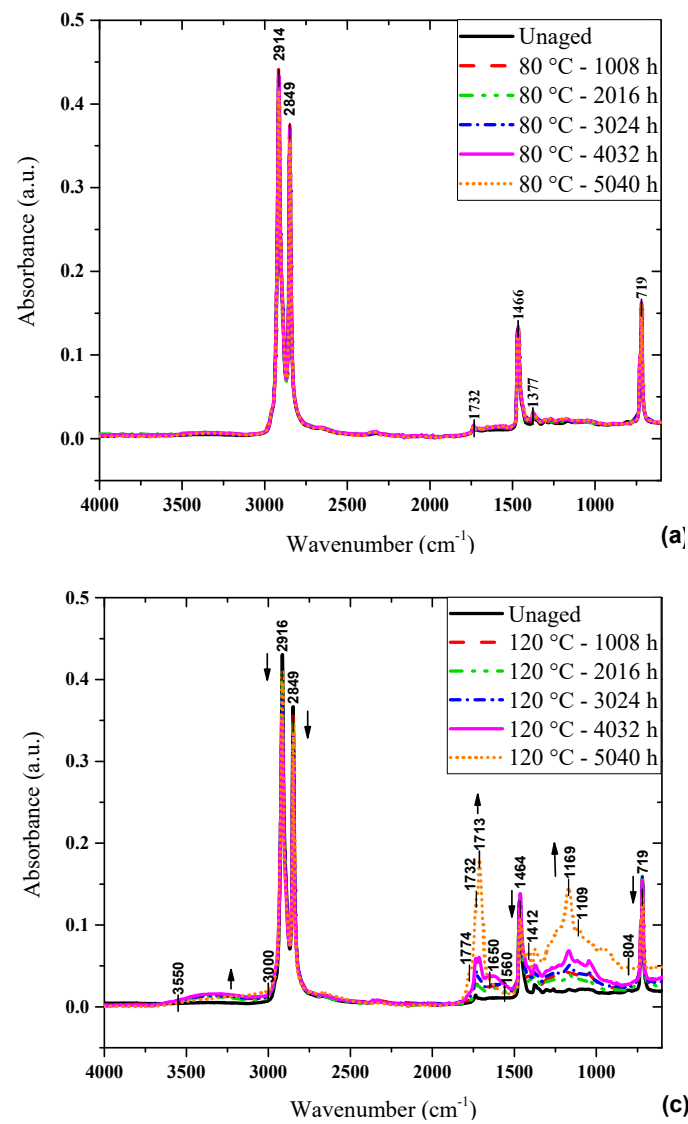

chemical functions related to the degradation of the material, the characteristic bands of the virgin XLPE have been found. The peak at wavelength of $719 \mathrm{~cm}^{-1}$ corresponds to the rocking methylene groups $-\mathrm{CH}_{2}$. The peak at $1466 \mathrm{~cm}^{-1}$ is attributed to the wag vibration of $-\mathrm{CH}_{2}$. The other peaks at $2849 \mathrm{~cm}^{-1}$ and $2914 \mathrm{~cm}^{-1}$ correspond respectively to symmetric and asymmetric stretching vibration of $-\mathrm{CH}_{2}$ group [15].

No significant change in the FTIR spectra of XLPE was observed after aging at 80 and $100{ }^{\circ} \mathrm{C}$. However, due to thermo-oxidative reactions, the main obtained changes in the FTIR spectra after aging at 120 and $140{ }^{\circ} \mathrm{C}$ consist in the formation of $\mathrm{C}=\mathrm{O}$ carbonyl groups. Three bands characteristic to the $\mathrm{C}=\mathrm{O}$ group are observed between 1650 and $1800 \mathrm{~cm}^{-1}$. The first one at $1713 \mathrm{~cm}^{-1}$ shows an absorption of the carboxylic acid and ketones $\left[\mathrm{RC}(=\mathrm{O}) \mathrm{OH}, \mathrm{RC}(=\mathrm{O}) \mathrm{R}^{\prime}\right]$, where $\mathrm{R}$ and $\mathrm{R}^{\prime}$ represent a chain of the aged polymer and its fragment, respectively. The second band at $1732 \mathrm{~cm}^{-1}$ characterizes the absorption of aldehyde or the ester $[\mathrm{RC}(=\mathrm{O})$ OR']. The third band corresponds at $1774 \mathrm{~cm}^{-1}$ and is attributed to the carboxylic anhydride [16].

On the other hand, the decrease of the IR absorption in the XLPE characteristic bands (719, 1466, 2849 and $2914 \mathrm{~cm}^{-1}$ ) after aging, could be a result of molecular chains scission. In addition, an increase of the IR absorption band between 800 and $1128 \mathrm{~cm}^{-1}$ is observed with aging. This band could be associated with the $\mathrm{C}=\mathrm{C}$ double bond of the unsaturated
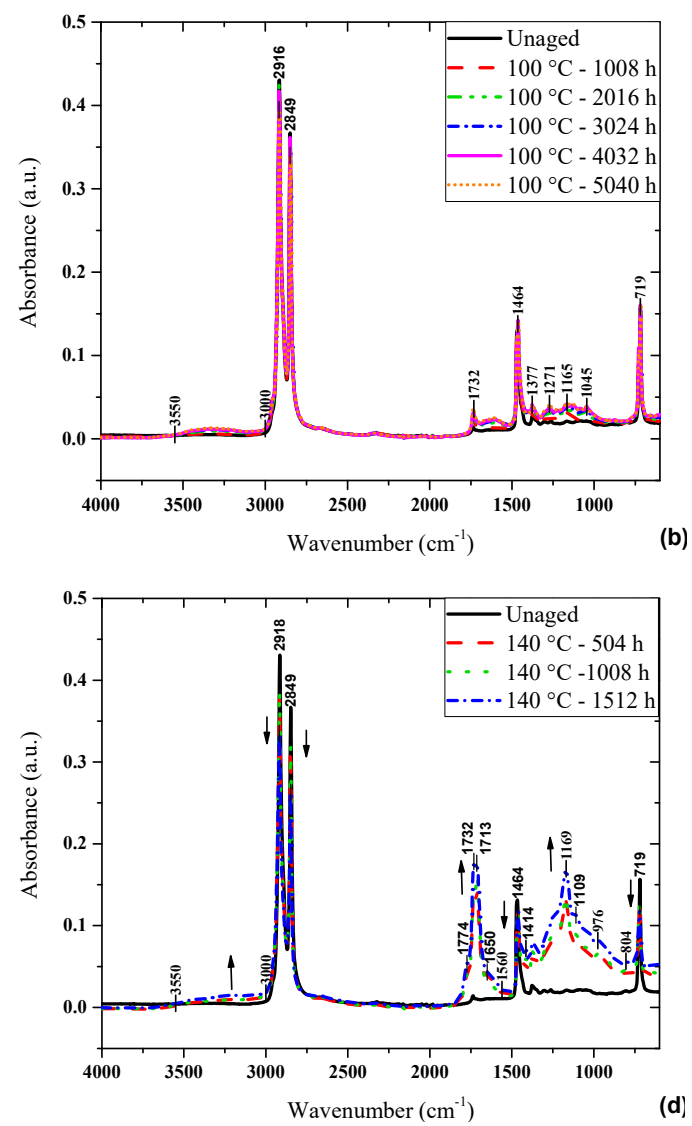

Figure 2. ATR- FTIR spectra of different XLPE samples aged at: (a) $80{ }^{\circ} \mathrm{C}$, (b) $100{ }^{\circ} \mathrm{C}$, (c) $120{ }^{\circ} \mathrm{C}$ and (d) $140{ }^{\circ} \mathrm{C}$. The up and down arrows indicate respectively the increase and the decrease of the chemical group absorbance. 
groups, vinylidene and trans-vinyl $[15,17]$. Also, the $\mathrm{C}=\mathrm{C}$ bond of the vinylene group could be found between 1560 and $1650 \mathrm{~cm}^{-1}$ [18]. Moreover, it is suggested that the increase in absorption between 1169 and $1414 \mathrm{~cm}^{-1}$ is associated with the vibrations of the $-\mathrm{C}-\mathrm{O}-\mathrm{C}-$ bond [15]. Finally, in the region between 3000 and $3500 \mathrm{~cm}^{-1}$, a slight increase in the absorption of the $-\mathrm{OH}$ function of the hydroxyl groups could be noticed after aging $[15,17]$.

Also, the IR absorption of the Irganox antioxidant, which is characterized by the presence of the C-O-C bond, was not detectable through ATR-FTIR analysis. This feature could be explained by the fact that the antioxidant absorption is superimposed on the IR absorption peaks of the oxidation products which occur at about 1078, 1159 and $3604 \mathrm{~cm}^{-1}$ [15].

During thermo-oxidative reactions, the radicals generated by chains scission of the polymer could react in the presence of oxygen with another polymer chain in order to generate a peroxyl radical $\mathrm{ROO}^{\circ}$. Then, this last radical could capture hydrogen atoms from other polymer chains to generate hydroperoxide $(\mathrm{ROOH})$ and alkyl $\left(\mathrm{R}^{\circ}\right)$ radicals and keep the oxidative reactions auto-accelerated [17]. The termination step involves all possible reactions between the two radicals $\mathrm{ROO}^{\circ}$ and $\mathrm{R}^{\circ}$. Also, it has been shown in reference [19] that peroxyl radicals could lead to the formation of a pair of alkoxy radicals $\left(\mathrm{RO}^{\circ}\right)$ in a cage. In references [19-20], several possible reaction paths are explored leading to a termination and also to a non-terminating combination (diffusion out of the cage leading to the priming of a new oxidation chain). Moreover, the reactions of alkoxy radicals could result in the formation of more polar and carbonyl groups such as aldehydes and ketones [21].

For the sake to obtain qualitative information concerning the chemical changes caused by the thermal aging, carbonyl products were evaluated by the carbonyl index $\mathrm{CI}$, characterized by the ratio of the relative intensities absorbed at $1732 \mathrm{~cm}^{-1}$ (absorption of the aldehyde) and $1466 \mathrm{~cm}^{-1}$ (methylene uptake). In addition, hydroxyl index HI was calculated as the ratio of the peak area of hydroxyl groups in the region between 3000 and $3500 \mathrm{~cm}^{-1}$, CI and HI are shown in Figure 3.

The presence of carbonyl groups has been observed in all samples, before and after aging. The CI of the virgin sample is low and it is caused by impurities from the manufacturing process. At aging temperatures of 80 and $100^{\circ} \mathrm{C}$, the growth rate of hydroxyl groups started earlier than that of carbonyl where $\mathrm{HI}$ begins to increase significantly after about $1008 \mathrm{~h}$ at $100{ }^{\circ} \mathrm{C}$ (Figure $3 \mathrm{~b}$ ). On the other hand, thermal aging at 80 and $100{ }^{\circ} \mathrm{C}$ had a very weak effect on CI which exceeded slightly the values of the virgin sample.

For aging temperature of $120{ }^{\circ} \mathrm{C}$, the thermo-oxidation process becomes more intense, which is reflected by a significant increase of both indexes. In addition, it has been noticed that $\mathrm{CI}$ increases rapidly at $120{ }^{\circ} \mathrm{C}$ after $4032 \mathrm{~h}$ of thermal aging. Moreover, the rise of $\mathrm{CI}$ is very fast at the beginning of aging at $140{ }^{\circ} \mathrm{C}$. It has been found also that after $504 \mathrm{~h}$ at $140{ }^{\circ} \mathrm{C}, \mathrm{CI}$ increases with aging time with a relatively slow rate (Figure 3a). Increasing the aging temperature obviously increases the rate of oxidation reaction and thus accelerates the generation of aging products.

Aging of XLPE at temperatures higher than the melting point (which is around $105{ }^{\circ} \mathrm{C}$ ) could facilitate the oxygen diffusion into the space between the molecular chains and then leads to accelerate thermo-oxidative reactions. As a result, CI and $\mathrm{HI}$ at high aging temperature are significantly greater than those at lower temperatures.

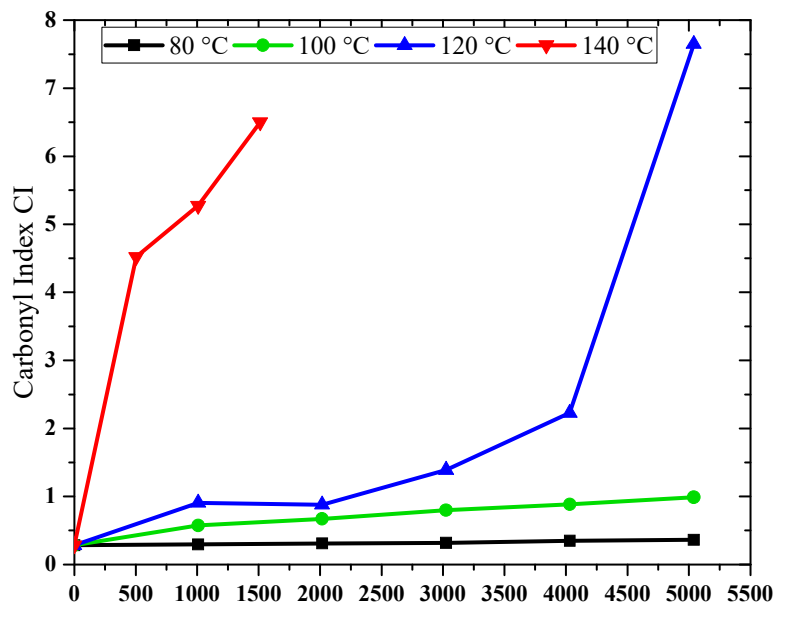

Ageing time (h)

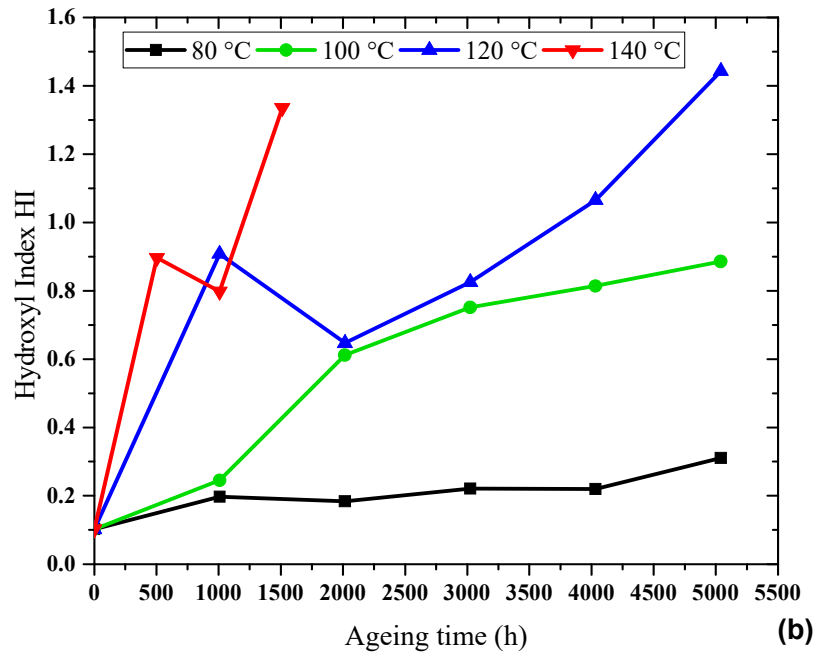

Figure 3. Evolution of (a) Carbonyl index and (b) Hydroxyl index, versus aging time.

\subsection{DSC RESULTS}

The DSC thermograms corresponding to the second heating and cooling cycles of the unaged and the aged XLPE samples are shown respectively in Figures 4 and 5. To provide quantitative analysis, we considered the melting $\left(T_{m}\right)$ and the crystallization $\left(T_{c}\right)$ temperatures, the enthalpies of fusion $\Delta H_{m}$ and of crystallization $\Delta H_{c}$, the endothermic peak shape and the lamellar thickness.

The crystallinity rate is calculated using the Equation 1:

$\chi_{c}=\frac{\Delta H_{m}}{\Delta H_{0}} \times 100 \%$

where $\Delta H_{0}$ is the theoretical melting enthalpy for the 
complete crystallinity PE, $\Delta H_{0}=287.3 \mathrm{~J} / \mathrm{g}[15]$. Besides, the average lamellar thickness was calculated based on Thompson-Gibbs equation as follows:

$$
L=\frac{T_{m_{0}}-T_{m}}{T_{m_{0}}} \frac{2 \sigma_{e}}{\Delta H_{m}}
$$

where $T_{m 0}$ is the equilibrium melting temperature of an infinitely thick crystal $T_{m 0}=414.6 \mathrm{~K}, T_{m}$ is the melting point, $\Delta H_{m}$ is the enthalpy of fusion and $\sigma_{e}=60.9 \times 10^{-3} \mathrm{~J}_{\mathrm{m}} \mathrm{m}^{-2}$ is the surface free energy per unit area of basal face [22] The obtained results by DSC experiments are presented in Table 1.

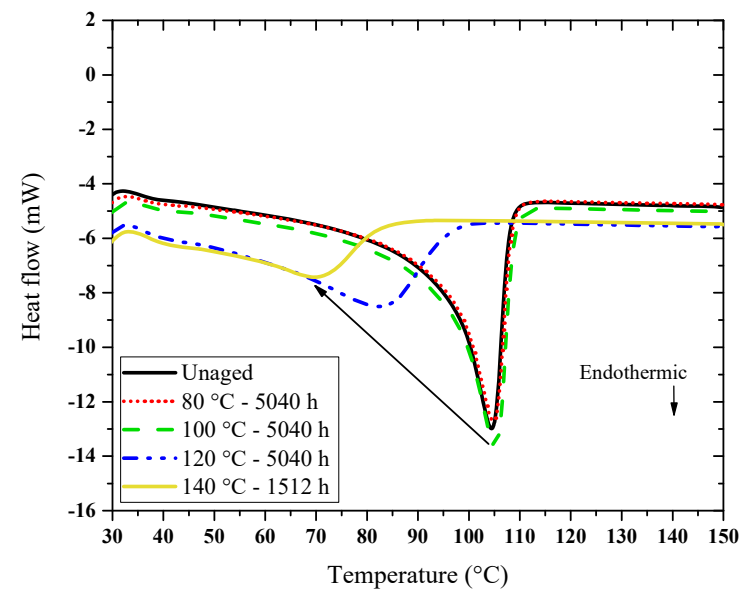

Figure 4. DSC heating thermograms of XLPE samples before and after thermal aging at $80,100,120$ and $140{ }^{\circ} \mathrm{C}$.

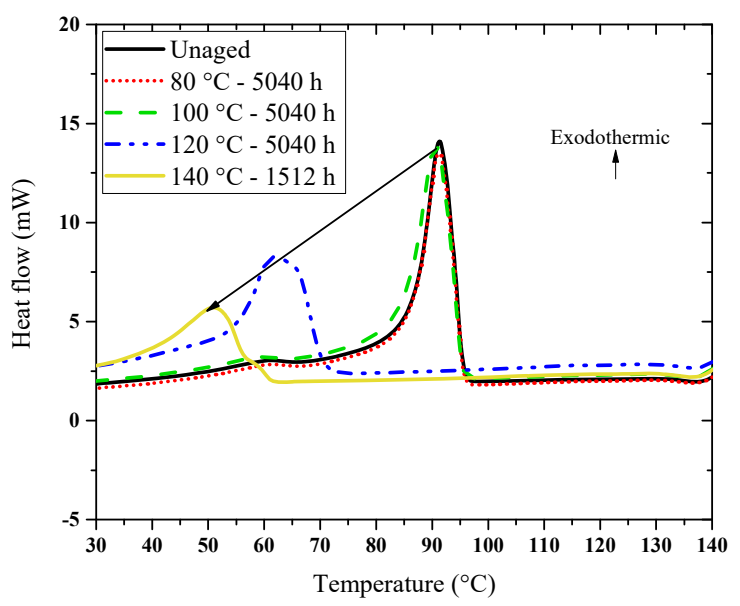

Figure 5. DSC cooling thermograms of XLPE samples before and after thermal aging at $80,100,120$ and $140{ }^{\circ} \mathrm{C}$.

Table 1. RESULTS OBTAINED FROM DSC MEASUREMENTS (SECOND SCAN).

\begin{tabular}{c|c|c|c|c|c}
\hline & Unaged & $\begin{array}{c}80{ }^{\circ} \mathrm{C}, \\
5040 \mathrm{~h}\end{array}$ & $\begin{array}{c}100{ }^{\circ} \mathrm{C}, \\
5040 \mathrm{~h}\end{array}$ & $\begin{array}{c}120^{\circ} \mathrm{C}, \\
5040 \mathrm{~h}\end{array}$ & $\begin{array}{c}140{ }^{\circ} \mathrm{C}, \\
1512 \mathrm{~h}\end{array}$ \\
\hline$T_{m}\left({ }^{\circ} \mathrm{C}\right)$ & 104.43 & 104.41 & 104.80 & 82.77 & 70.09 \\
$T_{c}\left({ }^{\circ} \mathrm{C}\right)$ & 91.17 & 90.52 & 91.30 & 61.85 & 51.05 \\
$\Delta H_{m}\left(\mathrm{~J} . \mathrm{g}^{-1)}\right.$ & -111.30 & -112.70 & -118.70 & -67.40 & -35.87 \\
$\Delta H_{c}\left({\mathrm{~J} . \mathrm{g}^{-1}}^{-1)}\right.$ & 113.80 & 110.80 & 117.40 & 66.80 & 39.75 \\
$\chi_{\mathrm{c}}(\%)$ & 39.75 & 40.25 & 42.39 & 24.08 & 12.81 \\
$\mathrm{~L}(\mathrm{~nm})$ & 4.74 & 4.73 & 4.78 & 2.99 & 2.45 \\
\hline
\end{tabular}

The DSC thermograms in Figure 4 show an endothermic peak associated with the melting of the crystalline part in XLPE material. As the degradation goes on, the area and the intensity of the melting and crystallization peaks decrease while it moves to lower temperatures. Additionally, one main exothermic peak, characterizing the XLPE crystallization temperature, appeared on all the thermograms of Figure 5. This peak is shifted toward lower temperatures after aging at 120 and $140{ }^{\circ} \mathrm{C}$. Therefore, based on DSC results, two steps of XLPE aging process could be distinguished.

The first step corresponds to aging temperatures below the melting point $\left(80\right.$ and $100{ }^{\circ} \mathrm{C}$ ), thermo-oxidation is inhibited by the antioxidant. Meanwhile, small parts of the lamellar crystals may melt and the oxidation mainly affects the amorphous regions. The lamellar thickness was practically not affected. In addition, low molecular weight segments could appear in the amorphous regions due to the scission of the ends of the macromolecular chains. These resulting segments crystallize and could act to enhance crystallization. This is known as a post-cross-linking phenomenon, which leads to higher homogeneity in the crystalline region. Hence, melting temperature, enthalpy of fusion, and crystallinity may increase slightly [17].

The second phase corresponds to the higher aging temperatures $\left(120\right.$ and $\left.140{ }^{\circ} \mathrm{C}\right)$, the oxidation becomes autoaccelerated rapidly since the antioxidant has been consumed. Also, more small chain segments and dangling bonds would be released as a consequence of the main chain scissions in XLPE [18]. The crystalline parts, then tend to disappear, which makes the diffusion of oxygen faster $[8,17]$.

\subsection{RESULTS OF THE FREQUENCY DIELECTRIC SPECTROSCOPY TEST}

\subsubsection{DIELECTRIC CONSTANT}

Figure 6 shows the evolution of the dielectric constant of XLPE samples at $20{ }^{\circ} \mathrm{C}$ for different aging conditions. The dielectric constant increases slightly as the frequency decreases. This increase is a little faster between about 10 and $10^{5} \mathrm{~Hz}$, which corresponds to the orientation polarization of dipoles [4].

Under $10 \mathrm{~Hz}$, the interfacial polarization (Maxwell-WagnerSillars) associated with the accumulated charges on the surfaces of the electrodes occur and the dielectric constant tends to a constant value. Moreover, the dielectric constant remains practically unchanged as the aging time increases at $80{ }^{\circ} \mathrm{C}$ (Figure 6a). At this temperature, the material is in a state of scleroid solidity and thermal oxidation has a negligible effect on the dielectric constant of XLPE [8].

On the other hand, Figure $6 \mathrm{~b}$ shows that the dielectric constant for the sample aged for $2016 \mathrm{~h}$ at $100{ }^{\circ} \mathrm{C}$ is greater than before aging. After that, it decreases with aging time and reaches a minimum after $5040 \mathrm{~h}$ with a value that is smaller than the unaged one. In fact, it can be assumed that when aging at temperatures below the melting point of the virgin sample (about $105{ }^{\circ} \mathrm{C}$ ), the combined effects of thermal oxidation and post-cross-linking occur simultaneously during aging as shown by FTIR and DSC tests. 

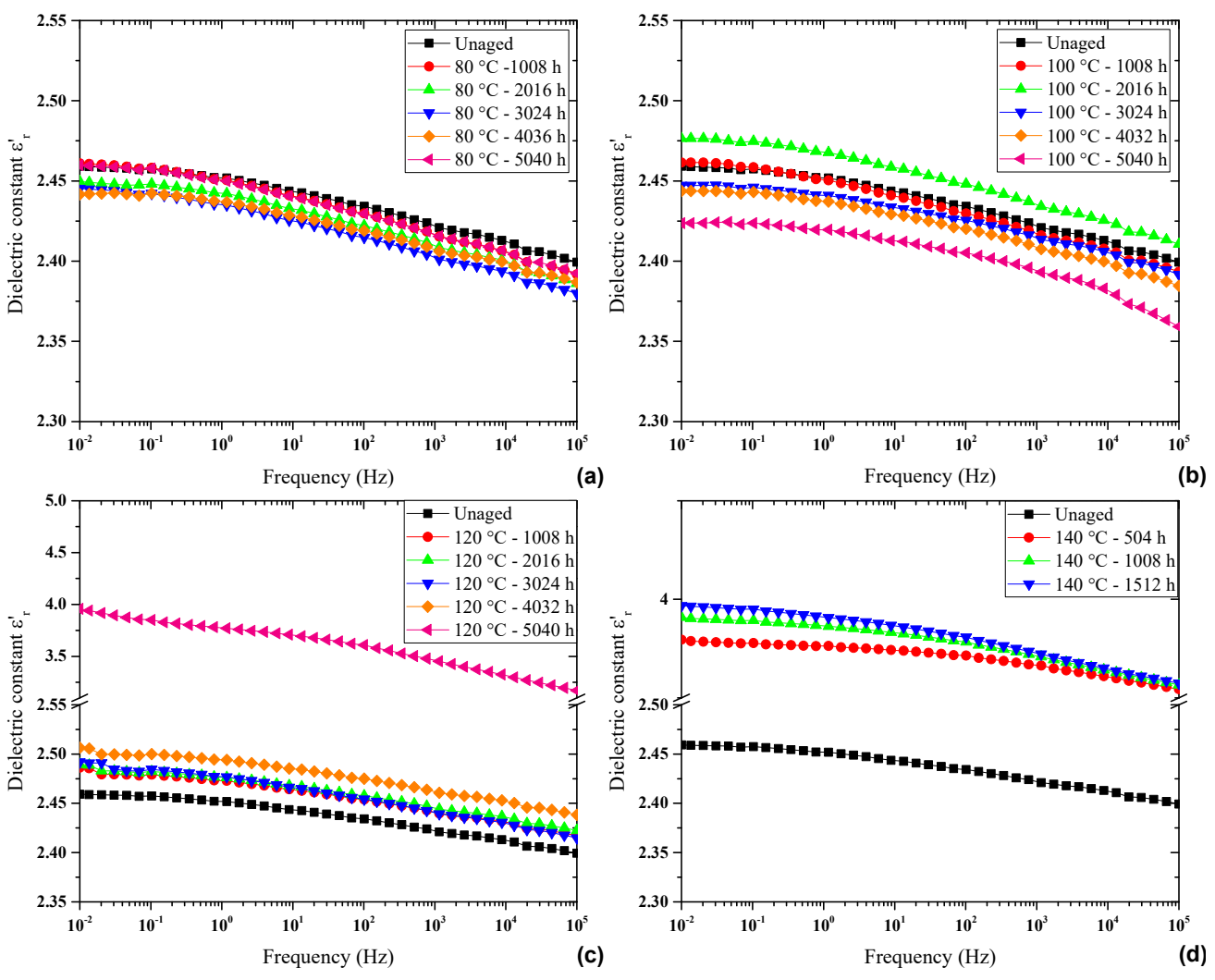

Figure 6. Variation of the dielectric constant of XLPE samples versus frequency at aging temperatures of: (a) $80{ }^{\circ} \mathrm{C}$, (b) $100{ }^{\circ} \mathrm{C}$, (c) $120{ }^{\circ} \mathrm{C}$ and (d) $140{ }^{\circ} \mathrm{C}$, for different durations.

Thermal oxidation reactions lead to the formation of polar groups, such as carbonyl, peroxide and hydroxyl groups, which contribute to increasing the dielectric constant. Nevertheless, the post-cross-linking could optimize the crystallinity of the samples leading to mitigate the accumulation of space charges and to make molecular orientation polarization more difficult [18]. Therefore, to our point of view the influence of thermal aging on XLPE samples would depend on which process is playing the dominating role, thermal oxidation or post-cross-linking and recrystallization. At the aging temperature of $100{ }^{\circ} \mathrm{C}$, small parts of the crystalline regions are melted and certain aging time is necessary (longer than $2016 \mathrm{~h}$ ) for the post-crosslinking to wield the dominant influence on the dielectric constant, which decreases with aging time $[8,18]$.

In contrast, when samples were aged at $120{ }^{\circ} \mathrm{C}$, the degradation process by thermo-oxidative reactions is quickly dominating. First, the dielectric constant increases slowly at the beginning of aging and remains almost unchanged until $3024 \mathrm{~h}$ but it then begins to increase over time, reaching a higher value after $5040 \mathrm{~h}$ (Figure 6c). At $140{ }^{\circ} \mathrm{C}$, chain scission by thermal oxidation overwhelms the post-crosslinking which leads to increase the amorphous phase and make the macromolecule chains more flexible to interact under the polarization effect. At the same time, more polar groups are being generated resulting in increasing the dielectric constant drastically.

Moreover, it can be seen in Figure 6d that the dielectric constant curves at $140{ }^{\circ} \mathrm{C}$ are very close at the high frequency end $(>1 \mathrm{kHz})$ and they are spaced out as the frequency decreases. In other words, the variation of the dielectric constant as a function of aging time is more important at low frequencies due to the local accumulation of space charges in XLPE [23]

\subsubsection{DIELECTRIC LOSSES FACTOR}

As far as the dielectric losses are concerned, we present in Figure 7 the variations of $\tan (\delta)$ of the XLPE for different thermal aging temperatures and durations. It can be observed that $\tan (\delta)$ is almost constant versus frequencies above $10^{2}$ Hz. This is associated with the $\beta$ relaxation due to the movement of molecular chains in the amorphous phase of XLPE $[4,23]$. In this range, the dielectric losses are attributed to the orientation polarization of dipoles. Also, it is well known that dielectric losses are generally related to interfacial polarization and to conduction at low frequencies.

During aging at 80 and $100{ }^{\circ} \mathrm{C}$, combined effects of thermal oxidation and recrystallization occur simultaneously, but remain practically without effect on the dielectric loss factor which shows a minimum peak around $0.1 \mathrm{~Hz}$. On the other hand, when the degradation becomes more accentuated, at 140 ${ }^{\circ} \mathrm{C}$ and after $5040 \mathrm{~h}$ at $120{ }^{\circ} \mathrm{C}$, the losses significantly rise. This behavior results from the generation of polar groups due to the decomposition of the material by thermal degradation.

In fact, it could be affirmed according to the DSC results that the clarity of the relaxation $\beta$ at high frequencies in the most degraded samples is due to the decrease of XLPE crystallinity after aging (increase of the amorphous part). 

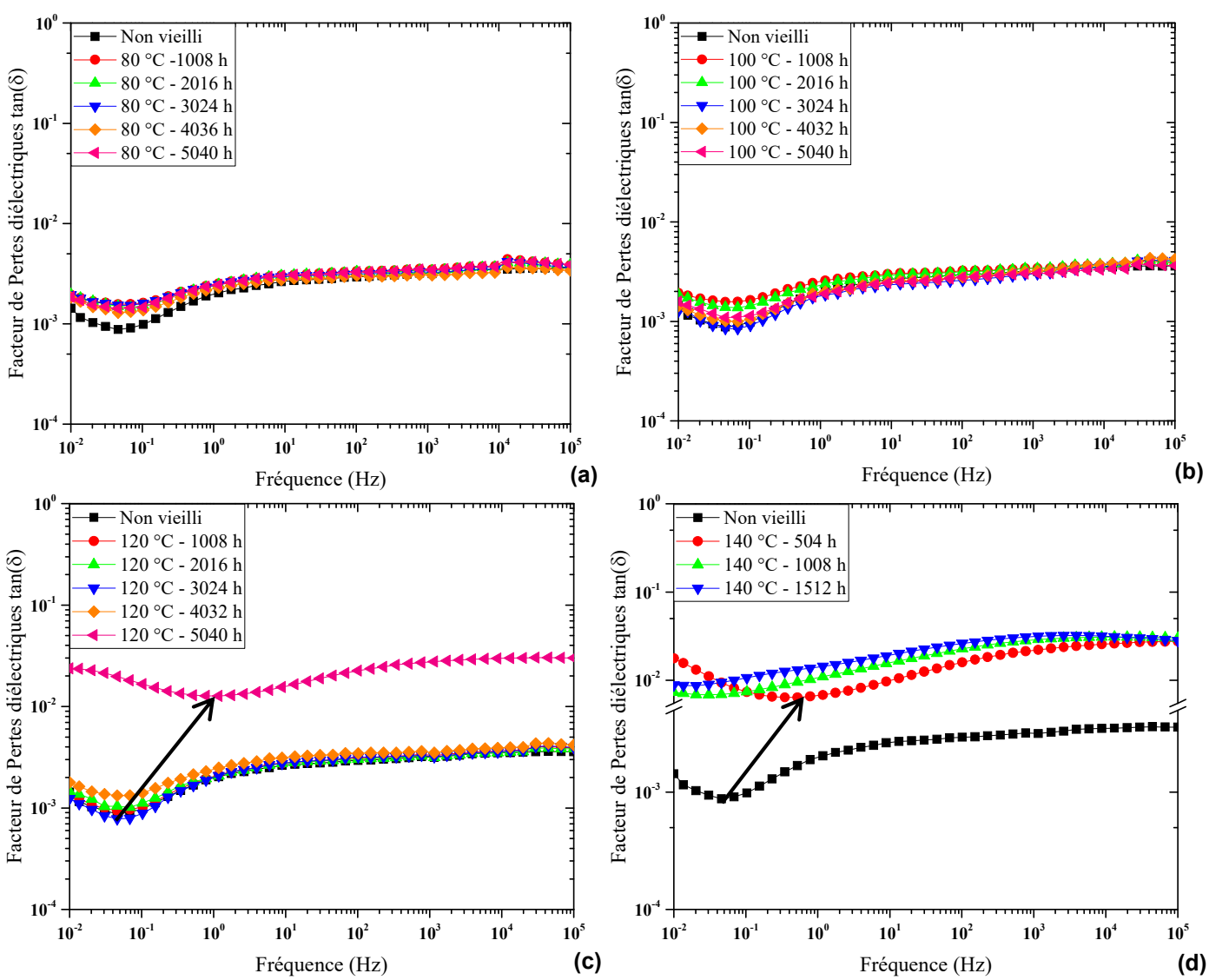

Figure 7. Variation of the dielectric constant of XLPE samples versus frequency at aging temperatures of: (a) $80{ }^{\circ} \mathrm{C}$, (b) $100{ }^{\circ} \mathrm{C},(\mathrm{c}) 120{ }^{\circ} \mathrm{C}$ and $(\mathrm{d}) 140{ }^{\circ} \mathrm{C}$, for different durations.

For instance, the sample aged for $5040 \mathrm{~h}$ at $120^{\circ} \mathrm{C}$ has a crystallinity degree of $24.07 \%$ (against $39.75 \%$ for the unaged sample as shown in Table 1) and $\beta$ relaxation peak intensity higher than that of the unaged XLE.

Moreover, in the case of samples aged at $120^{\circ} \mathrm{C}$ for $5040 \mathrm{~h}$ and at $140{ }^{\circ} \mathrm{C}$ for $504 \mathrm{~h}$, the displacement of $\tan (\delta)$ curves towards high frequencies (as indicated by arrows in Figure 7) could be attributed to the non-homogeneity of the physical structure of the material which could also be reflected by the non-homogeneity of the color of the samples (Figure 1d and 1e). The non-homogeneity of the XLPE color seems to indicate the effect of increasing the interfacial zones and then promoting losses by Maxwell-Wagner-Sillars polarization at short times (high frequencies). This result remains very important indicating the advanced degradation state of XLPE material.

\section{CONCLUSION}

The physicochemical changes occurring in XLPE samples during thermal aging were investigated and put in relation to changes in the dynamic dielectric behavior of the insulating material. The results can be summarized as follows:

1) FTIR characterization results show that the chemical degradation of XLPE during thermal aging includes mainly the consumption of the antioxidant followed by thermo- oxidative reactions. Chemical degradation is accompanied by the generation of polar groups such as carbonyl, peroxide and hydroxyl groups.

2) The color change of XLPE to dark orange may reflect the beginning of the material deterioration. This change is attributed to the formation of vinylidene and vinyl groups.

3) DSC experiments show that the physical degradation consists in the deterioration of the crystalline structure of XLPE and decreasing of the melting temperature.

4) Post-cross-linking reactions could occur at the beginning of aging which leads to improve the thermal and dielectric properties due to the recrystallization of some parts in XLPE as shown by DSC results.

5) As the thermal stress increases, thermo-oxidative reactions cause molecular chain scission and generation of more polar groups.

6) Through the dielectric spectroscopy measurements, it was found that analysis at the low frequencies range seems to be more useful for evaluating the advanced degradation of XLPE samples.

7) The origin of dielectric losses at low frequencies is the interfacial polarization due to the space charge accumulated in the volume of the insulation, in particular, near the electrodes. 8) The non-homogeneity of XLPE color seems to indicate the increase of interfaces in the material which could lead to rise the dielectric losses due to the interfacial polarization. 
To sum up, the aging process can be divided into two phases: at the beginning of aging, the mechanisms of degradation are inhibited by the antioxidant introduced into the material. Also, post-cross-linking reactions could occur which leads to decrease the polarization due to the recrystallization of some parts in XLPE. During the second phase of aging, as the thermal stress increases, thermooxidative reactions take the leading role, which causes molecular chain scission and generation of more polar groups. This implies a significant increase in the dielectric constant and the dielectric losses, mainly at low frequencies. The nonhomogeneity color (structure) of aged XLPE could be very dangerous as it may indicate the appearance of more interface areas that enhances space charges accumulation.

\section{REFERENCES}

[1] T. Liu, "Dielectric Spectroscopy of Very Low Loss Model Power Cables,". PhD dissertation, Dept. of Eng., University of Leicester, England, Feb. 2010.

[2] G. Teyssedre and C. Laurent, "Advances in High-Field Insulating Polymeric Materials Over the Past 50 Years," IEEE Electr. Insul. Mag., vol. 29 , no.5, pp. 26-36, Oct. 2013.

[3] I. A. Metwally, "The Evolution of Medium Voltage Power Cables," IEEE Potentials., vol. 31, no. 3, pp. 20-25, May. 2012.

[4] M. Nedjar, "“Effect of thermal aging on the electrical properties of crosslinked polyethylene," J. Appl. polymer Sci., vol. 111, no. 4, pp. 1985 1990, Feb. 2009

[5] D. Andjelkovic, and N. Rajakovic, "Influence of accelerated aging on mechanical and structural properties of cross-linked polyethylene (XLPE) insulation,” IEEE, Electr. Eng., vol. 83, no. 1-2, pp. 83-87, Feb. 2001.

[6] J. V. Gulmine, and L. Akcelrud, "Correlation between structure and accelerated artificial aging of XLPE,” Eur. Polym. J., vol. 42, no. 3, pp. 553-562, Mar. 2006.

[7] H. Li, J. Li, Y. Ma, Q. Yan, and B. Ouyang "The role of thermo-oxidative aging at different temperatures on the crystal structure of cross-linked polyethylene," J. Mater. Sci: Mater. Electron., vol. 29, no. 5, pp. 36963703, Mar. 2018.

[8] D. He J. Gu, W. Wang, S. Liu, S. Song, and D. Yi, "Research on mechanical and dielectric properties of XLPE cable under accelerated electrical-thermal aging," Polym. Advan. Technol., vol. 28, no. 8, pp. 1020-1029, Sep. 2017.

[9] C. Kim, Z. Jin, P. Jiang, Z. Zhu, and G. Wang, "Investigation of dielectric behavior of thermally aged XLPE cable in the high-frequency range," Polym. Test., vol. 25, no. 4, pp. 553-561, Jun. 2006.

[10] J. Li, H. Li, Q. Wang, X. Zhang, B. Ouyang and J. Zhao, "Accelerated inhomogeneous degradation of XLPE insulation caused by copper-rich impurities at elevated temperature," IEEE Trans. Dielectr. Electr. Insul., vol. 23, no. 3, pp. 1789-1797, Jun. 2016

[11] C. C. Zhang, Y. F. Li, M. Y. Hu, F. L. Ma, H. Zhao and B. Z. Han, "Conductivity properties of XLPE insulation used for HVDC cable after accelerated thermal aging," 12th Inter. Conf. Prop. Appl. Dielect. Mater. (ICPADM), Xi'an, 2018, pp. 500-503.

[12] Guide for the determination of thermal endurance properties of electrical insulating materials. Part 1: General guidelines for aging procedures and evaluation of test result, IEC Standard 60216, 1991.

[13] Y. Kemari, A. Mekhaldi and M. Teguar, "Experimental investigation and signal processing techniques for degradation assessment of XLPE and PVC/B materials under thermal aging," IEEE Trans. Dielectr. Electr. Insul., vol. 24, no. 4, pp. 2559-2569, Sep. 2017.

[14] G. Teyssedre and C. Laurent, "Semi-quantitative analysis of photoluminescence in thermoelectrically aged cables: I-identification of optical signatures," IEEE Trans. Dielectr. Electr. Insul., vol. 16, no. 4, pp. 1180-1188, Aug. 2009.

[15] A. M. Nobrega, M. L. B. Martinez et A. A. A. de Queiroz, "Investigation and analysis of electrical aging of XLPE insulation for medium voltage covered conductors manufactured in Brazil," IEEE Trans. Dielectr. Electr. Insul., vol. 20, no. 2, pp. 628-640, Apr. 2013.

[16] C. Stancu, P. V. Notingher, P. Notingher et M. Lungulescu, "Space charge and electric field in thermally aged multilayer joints model," IEEE Trans. Dielectr. Electr. Insul., vol. 23, no. 2, pp. 633-644, Apr. 2016.
[17] B. Ouyang, H. Li, X. Zhang, S. Wang and J. Li, "The role of microstructure changes on space charge distribution of XLPE during thermooxidative aging," IEEE Trans. Dielectr. Electr. Insul., vol. 24, no. 6, pp. 3849-3859, Dec. 2017.

[18] Y. Liu, H. Liu, L. Yu, Y. Li and L. Gao, "Effect of thermal stress on the space charge distribution of $160 \mathrm{kV}$ HVDC cable insulation material," IEEE Trans. Dielectr. Electr. Insul., vol. 24, no. 3, pp. 1355-1364, Jun. 2017.

[19] M. Da Cruz, L. Van Schoors, K. Benzarti, and X. Colin, "Thermo-oxidative degradation of additive free polyethylene. Part I. Analysis of chemical modifications at molecular and macromolecular scales.” J. Appl. Polym. Sci., vol. 133, no. 18, 43287, Jan. 2016.

[20] N. Fuse, H. Homma and T. Okamoto, "Remaining issues of the degradation models of polymeric insulation used in nuclear power plant safety cables," IEEE Trans. Dielectr. Electr. Insul., vol. 21, no. 2, pp. 571-581, Apr. 2014

[21] N. Khelidj, X. Colin, L. Audouin, J. Verdu, C. Monchy-Leroy, V. Prunier, "Oxidation of polyethylene under irradiation at low temperature and low dose rate. Part I. The case of "pure" radiochemical initiation," Polym. Degrad. Stab., vol. 91, no. 7, pp. 1593-1597, Jul. 2006.

[22] L. Contat-Rodrigo, and AR. Greus, "Biodegradation studies of LDPE filled with biodegradable additives: Morphological changes. I," J. Appl Polym. Sci., vol. 83, no.8, pp. 1683-1691, Feb. 2002.

[23] J. Y. Li, X. T. Zhao, G. L. Yin, S. T. Li, J. K. Zhao, and B. H. Ouyang, "The effect of accelerated water tree aging on the properties of XLPE cable insulation," IEEE Trans. Dielectr. Electr. Insul., vol. 18, no. 5, pp. 1562- 1569, Oct. 2011

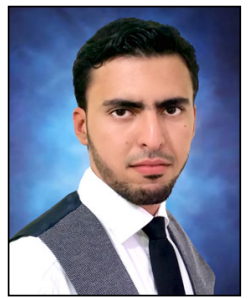

Youcef Kemari (S'17) was born in 1991. He obtained the degree of Engineer and the MSc degree in Power Electrical Engineering in 2013 from Ecole Nationale Polytechnique (ENP) in Algiers, Algeria. $\mathrm{He}$ is currently pursuing his Ph.D. degree at the Electrical Engineering Department at ENP. During his research, he focused on polymeric cables insulation, signal processing methods, artificial intelligence techniques and the optimization of grounding systems.

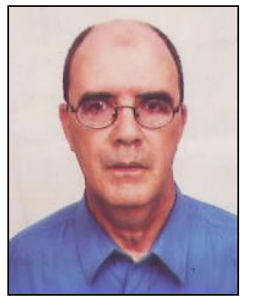

Abdelouahab Mekhaldi (SM'07) received the degree of Engineer in 1984 in electrical engineering, the MSc degree in 1990 and a Ph.D. in high voltage engineering in 1999 from Ecole Nationale Polytechnique (ENP) of Algiers. He is currently a Professor at ENP. His main research areas are in discharge phenomena, outdoor insulators pollution, polymeric cables insulation, lightning, artificial intelligence application in high voltage insulation diagnosis and electric field calculation.

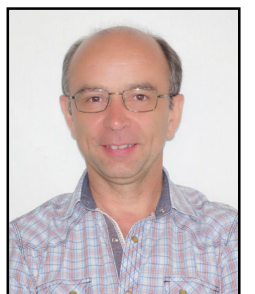

Gilbert Teyssedre was born in May 1966 in Rodez, France. He received his Engineer degree in materials physics and graduated in solid state physics in 1989 at the National Institute for Applied Science (INSA). Then he joined the Solid State Physics Lab in Toulouse and obtained the Ph.D. degree in 1993 for work on ferroelectric polymers. He entered the CNRS in 1995 and has been working since then at the Electrical Engineering Lab (now LAPLACE) in Toulouse. His research activities concern the development of luminescence techniques in insulating polymers with focus on chemical and physical structure, degradation phenomena, space charge and transport properties. He is currently Research Director at CNRS in a team working on the reliability of dielectrics in electrical equipment.

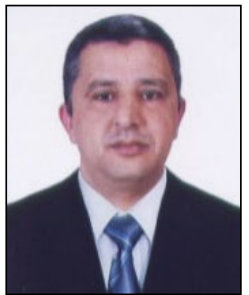

Madjid Teguar has obtained a first degree in electrical engineering in 1990, the MSc degree in 1993 and a Ph.D. in high voltage engineering in 2003 from Ecole Nationale Polytechnique (ENP) of Algiers. He is now a Professor in electrical engineering at ENP. His research interests are in insulation systems, insulation coordination, earthing of electrical energy systems and polymeric cables insulation. 